\title{
Perceived Meanings by Women and Men in "Identical Twins and Best Friends" Olay Advertisement
}

\author{
Fransisca Theresia Kurniawan \\ English Department, Faculty of Letters, Petra Christian University, Surabaya, East Java, Indonesia \\ e-mail: fransiskatheresia7@gmail.com
}

\begin{abstract}
This study observes the perceived meanings produced by women and men as respondents from different gender group can produce different perceived meanings. Using process of signification, the study of myth and decoding, the writer analyzed how meanings are perceived in Olay "Identical Twins And Best Friends" video commercial. The study uses descriptive qualitative approach. The finding is that in perceiving, women respondents are more likely to relate the women in the video with themselves about beauty, their own experience, and relationship with their sisters; while men respondents are most likely to relate them with their ideal type of women, older people and other female friends. Through this study, the writer expects that the result will help the readers understand the influence of gender in perceiving meanings from an advertisement.
\end{abstract}

Key words: Myth, Process of Signification, Sign, Signifier, Signified, Perceived Meaning.

\section{INTRODUCTION}

There are so many types of advertisements, but their goal/objective is the same which is to attract the potential customers. There are so many companies which promote their products attractively. One of them is Olay Company. This time, Olay has released its new campaign which is "Best Beautiful Stories" which you can find it on Olay official YouTube channel. Olay reinforced the customers to send their stories and the best story will be made into a video advertisement.

According to a global survey of Dove (Unilever, Tbk, 2017) which was given for 3200 women in their 18-64 years old in which it found that only $4 \%$ of women around the world consider themselves beautiful. However, the research found $80 \%$ of women agree that every woman has something about her that is beautiful, but do not see their own beauty. However, what men perceive about beauty is also different from women. According to the data given by the Department of Clinical, Educational, and Health Psychology at University College London (Swami, V, et. al., 2010), a sample was given to 2157 male University students. The result showed that men found the women in the picture are more beautiful with good personality information such as confidence, openness, kindness, and also the ones who smile often.

Thus, in this research, the writer has an objective to find out the perceived meanings which are produced by men and women of "Identical Twins and Best Friends" Olay advertisement and what the differences are. In order to understand the meaning, the writer will use process of significance, myth and decoding to tell the message through the images and words in Olay advertisements.

According to Chandler (Chandler, 2007), in process of signification, the sign must have signifier which is related to our sensory, and signified which is the meaning. While myth (Barthes, 1987) actually also refers to something that we hear and see, and make it more real and universal which it could also be a false idea. Moreover, according to Stuart Hall (Hall, S., 1980), decoding is the process of interpreting a message sent by an addresser to an addressee and helps the people to understand how representation could make the meaning in such ways. 


\section{METHODS}

The writer used descriptive qualitative approach (Schreier, 2012), because this approach is suitable with the research, since the writer wanted to reveal the individual interpretation in describing the meaning and the data also were in the form of text and pictures (not in the form of numeric data). The sources of the data were limited to one video of Olay "Identical Twins and Best Friends" advertisement in which it could be found on Olay North America Official YouTube channel. The subjects of this research were 20 respondents consisting of 10 men and 10 women whose ages are between 20 25 years old from Petra Christian University. The main instrument of this research was the writer herself since she was the one who collected and analyzed the data from the mentioned source above.

For procedure of data collection, firstly, the writer gathered the source of the data. The writer downloaded the "Identical Twins and Best Friends", saved it in her laptop, and made translation. After that, the writer established verbal and non verbal expressions to be asked in the interview section. Thirdly, the writer made a questionnaire in order to know the respondents' background information. Furthermore, the writer made interview questions and set the interview session. Lastly, the writer would put all the data in the form of table and analyze them.

Moreover, method of data analysis was the next step after collecting the data. The writer started to analyze each men and women group's perceived meanings of both verbal and non verbal expression. The writer here gave the tables of the pictures and questions that the writer used for the interview.

Table 1. Both women and men respondents of non verbal expression.

\begin{tabular}{|c|c|c|c|c|c|}
\hline No & $\begin{array}{c}\text { Do you think } \\
\text { the women } \\
\text { in the video } \\
\text { are } \\
\text { beautiful? }\end{array}$ & $\begin{array}{c}\text { Do their attitude } \\
\text { that is shown in } \\
\text { the video suit with } \\
\text { the attitude of } \\
\text { women in } \\
\text { general? Like } \\
\text { gentle, elegant, or } \\
\text { tender-hearted? }\end{array}$ & $\begin{array}{c}\text { What is the } \\
\text { relation between } \\
\text { those attitudes } \\
\text { with beauty? }\end{array}$ & $\begin{array}{c}\text { Do you think } \\
\text { the women here } \\
\text { like their own } \\
\text { face and body? }\end{array}$ & $\begin{array}{c}\text { Do you think } \\
\text { the women } \\
\text { in the video } \\
\text { look } \\
\text { confident? }\end{array}$ \\
\hline
\end{tabular}

Table 2. Both women and men respondents of verbal expression.

\begin{tabular}{|c|c|c|c|c|c|}
\hline No & \multicolumn{5}{|c|}{ What are the meanings of the verbal expressions below? } \\
\cline { 2 - 6 } & $\begin{array}{c}\text { We feel most } \\
\text { beautiful when } \\
\text { we're together }\end{array}$ & $\begin{array}{c}\text { Her skin look } \\
\text { flawless and } \\
\text { beautiful }\end{array}$ & $\begin{array}{c}\text { I don't think } \\
\text { we're aging } \\
\text { because I don't } \\
\text { feel my age }\end{array}$ & $\begin{array}{c}\text { I have got my } \\
\text { sister who can } \\
\text { give me the } \\
\text { confidence }\end{array}$ & $\begin{array}{c}\text { She makes me } \\
\text { feel better } \\
\text { about myself }\end{array}$ \\
\hline
\end{tabular}

\section{FINDINGS AND DISCUSSION}

The analysis is started with women respondents, and continued with men respondents.

- The analysis of perceived meanings from women respondents (nonverbal data)

Here, the writer would start it from nonverbal data and continued with verbal data. 


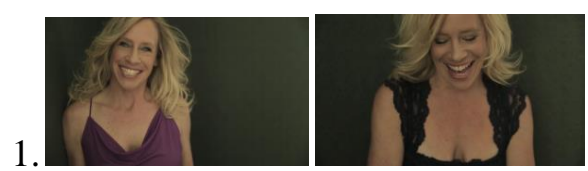

Figure 1. Pictures of the women in the video

Based on the first pictures, the writer asked question to 10 women respondents: Do you think the women in the video are beautiful?. In this part, the writer found 8 from 10 women (R1, R2, R3, R5, R6, R7, R8, and R10) agreed that the women in the video are beautiful because of their physical appearance: white skin. The women respondents here might still follow the traditional concept of beauty which considers white skin as beautiful and dark skin not beautiful. Here, it might also become a myth (Chandler, 2007) that culturally accepted among the societies that white skin is somehow more beautiful and powerful. Moreover, in the data, it also shows that 6 respondents (R2, R3, R5, R7, R8, and R10) saw the women are beautiful because they have Caucasian physical appearance. It might actually because most of Indonesians adore western people since they may look more powerful, dominant and have physical appearance that Indonesians mostly want, such as, pointed nose. Besides, 7 respondents (R1, R2, R5, R6, R8, R9, and R10) thought that women who smile a lot are beautiful. It might be interpreted that the ones who display positive expression like women in the video, are the ones whom they can get along with, make you relax, and feel more comfortable to open up.

2.

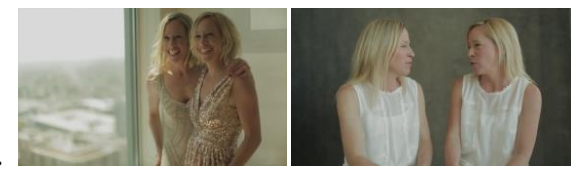

Figure 2. Photo shoots and interview section

Based on the second pictures, the writer asked question to 10 women respondents: Do their attitude that is shown in the video suit with the attitude of women in general? Like gentle, elegant, or tender-hearted?. All 10 women (R1, R2, R3, R4, R5, R6, R7, R8, R9 and R10) agreed that the women's attitudes in the video suit with the attitude of women in general, because of their smile. It might be interpreted that smiling actually shows friendliness and could be seen as more attractive. In addition, 5 of 10 women (R1, R2, R3, R4, and R8) agreed that women in the video who sit politely show that they have the same attitude with other women. Women in the video who sit politely may actually show a good etiquette.

3.
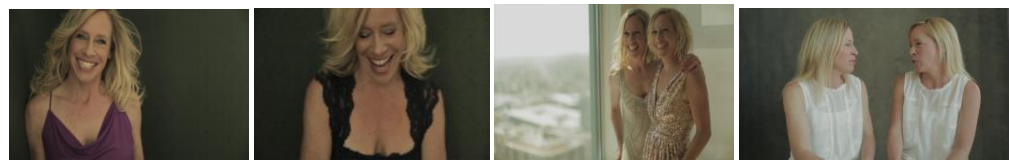

Figure 3. Pictures, photo shoot, and interview section

Based on these pictures, the writer asked question to 10 women respondents: What is the relation between those attitudes with beauty? 8 from10 women respondents here (R1, R2, R4, R5, R6, R7, R8, and R9) think that women who follow the attitude that the society has taught are beautiful. It could be interpreted that women in the video were and are expected to have attitude like other women in general because the society still follow the traditional concept of having a good manner is considered as beautiful. Women in the video might be told to have good attitude, like caring for others, comfort, respecting, and/or even listening more.

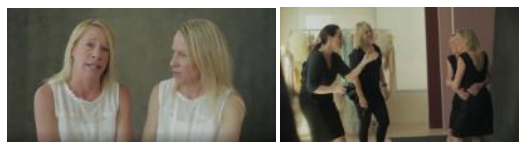


Figure 4. Second interview and photo shoot section pictures

Based on these pictures, the writer asked question to 10 women respondents: Do you think the women here like their own face and body?. Here, all women respondents (R1, R2, R3, R4, R5, R6, R7, $\mathrm{R} 8, \mathrm{R} 9$, and R10) thought that the women like their own face and body from the psychological perspective, which is smiling a lot and being confident. It could be interpreted that their smile is sincere in which that women who smile a lot may actually show that they are grateful and can accept themselves. They are confident because they might be not ashamed with their physical appearance and wear sleeveless shirt although the respondent thinks that they have big arms. Furthermore, 3 out of 10 women respondents (R2, R6, and R10) think that women in the video like their own face and body from their physical appearance. If women do not like their face, they may cover it with thick and heavy makeup so that their imperfection like their wrinkles, dark circles, and else will be covered. However, women in the video do not cover their wrinkles with heavy makeup.

5.

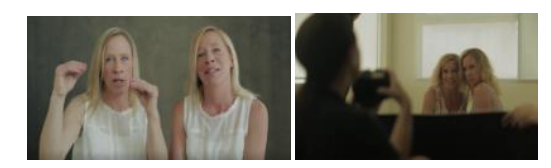

Figure 5. Women's talks and pose when they are being photographed

Based on these pictures, the writer asked this question to 10 women respondents: Do you think the women in the video look confident?. First of all, 8 women respondents (R2, R3, R4, R5, R6, R7, R8, and R10) thought that the women look confident from the psychological perspective, in which they want to be photographed and smile naturally. It could be interpreted that they smile naturally as if they were not being interviewed. If women in the video were not confident, they might not like if people take a picture of them and might be afraid and anxious. Furthermore, 7 from 10 women (R1, R3, R4, R6, R7, $\mathrm{R} 8$, and R10) agreed that women look confident because they speak naturally. It could be interpreted that women in the video talk clearly and their talk does not look nervous or shy. It might be because their talk looks concise enough and comes across clearly.

- The analysis of perceived meanings from women respondents (verbal data)

After the writer analyzed women respondents' perceived meanings from the nonverbal data, the writer continued with the verbal data.

1. We feel most beautiful when we're together

Based on the above verbal expression, taken from the video, the writer asked the meaning that they can get. First of all, all women respondents (R1, R2, R3, R4, R5, R6, R7, R8, R9, and R10) agreed that the women in the video feel most beautiful because of their good relationship. It could be interpreted that since they love and are very close to each other, they might give a truly heartfelt praising in which she then feels appreciated and confident. Moreover, 3 out of 10 women respondents (R6, R7, and R10) agree that it is because they feel more powerful. It might be interpreted that powerful here means not afraid with negative things, like gossiping, insulting. In addition, 5 of 10 women (R4, R5, R7, R8, and R10) respondents think that they feel most beautiful when they are together because they are twins. It may be because people think twins are more outstanding and extraordinary.

2. Her skin looks flawless and beautiful

First of all, 5 women respondents (R2, R3, R4, R7, and R9) agreed that woman in the video said her skin looks flawless and beautiful, because of their good relationship. It may be because she is really close to each other since they were kid, and the fact that they are twins. Furthermore, the writer also found that there are 8 women respondents (R1, R2, R4, R5, R6, R8, R9 and R10) who think that the women said her skin looks flawless and beautiful, because they are confident. It might be because their talks look convincing in which people could be convinced to also think that her skin is beautiful. 
3. I don't think we're aging because I don't feel my age

For the first analysis, 4 women respondents (R1, R2, R5, and R6) perceived that they say it because they are confident and positive thinking. It may be, because they have more self esteem. Since they always think positively and do self praising, they could boost their confident. In addition, 8 women respondents (R2, R3, R4, R5, R6, R8, R9 and R10) perceived that they say it because they want to be like a youngster. It could be interpreted that women in the video do not want to look like other mid-age people. That may be why they do self praising and say positive words in order to be like 18 years old do; active, passionate, fresh, and have dreams or goals to reach.

4. I have got my sister who can give me the confidence

For the first analysis, all 10 women respondents (R1, R2, R3, R4, R5, R6, R7, R8, R9 and R10) perceived that the woman in the video said I have got my sister who can give me the confidence, because of their close relationship. It might be because her sister always compliments her that she is still beautiful, then, she might believe that what her sister said is true rather than anyone else. In addition, there is one woman respondent (R6) who perceives that as mirror reflection. It may be because they are twins who have the same face, do the same things, and are always together since they were born.

5. She makes me feel better about myself

First of all, all 10 women respondents (R1, R2, R3, R4, R5, R6, R7, R8, R9 and R10) perceived that the woman in the video said "She makes me feel better about myself", because of their close relationship. Her sister might be a place when she is down / has a problem. She might ask for advice and compliment to make her feel better; since she thinks that her sister will do it for her. Secondly, 5 women respondents (R1, R2, R3 R7 and R10) perceive that it is related with being confident. It could be interpreted that her sister might make her feel better because she always compliments, supports, and motivates her.

- The analysis of perceived meanings from men respondents (nonverbal data)

Below are the analyses for men respondents' perceived meanings from non verbal data.

1.

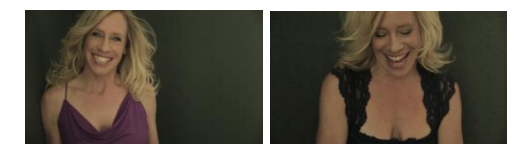

Figure 1. Pictures of the women in the video

Based on these pictures, the writer asked question to 10 men respondents: Do you think the women in the video are beautiful?. In this part, the writer found there 9 men respondents (R11, R12, R13, R14, R15, R16, R17, R18, and R19) who agreed that the women in the video are beautiful and only one man respondent (R20) who thinks that they are not beautiful. For the first analysis, 7 men respondents (R11, R13, R14, R15, R16, R17, and R18) agreed that women in the video are beautiful because of their physical appearance: twins. It could be interpreted that having the same face might become the center of attention, be more outstanding and look special. Moreover, 5 women respondents (R11, R13, R14, R16, and R18) think that they are beautiful because of their proportional body. It might be interpreted that proportional body look healthier than if the women were obese / too slim. In addition, one man respondent (R20) thinks that the women in the video are not beautiful, because they look narcissistic. It could be interpreted that for R20, women should not always say that they are beautiful. It could also be interpreted that R20 may not like the way they talk. If they did not always say that they are beautiful, R20 might think that the women are beautiful. 
2.

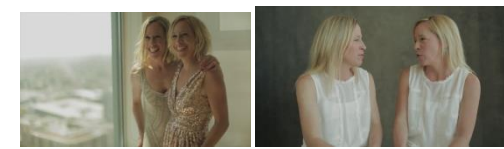

Figure 2. Photo shoots and interview section

Based on these pictures, the writer asked question to 10 men respondents: Do their attitude that is shown in the video suit with the attitude of women in general? Like gentle, elegant, or tender-hearted?. In this part, 9 men respondents (R11, R12, R14, R15, R16, R17, R18, R19 and R20) agreed that their attitudes are the same and only one man respondent (R13) who thinks that their attitudes do not suit with women in general. For the first analysis, 8 men respondents (R11, R14, R15, R16, R17, R18, R19 and R20) perceived that the women in the video have the same attitude with women in general from psychological perspective. It could be interpreted that women might smile often because they may be more expressive and emotional. Moreover, 3 respondents (R11, R16 and R18) perceive that it suits with women in general because they are open. It might be interpreted that women in the video might like to tell their stories because they may just want to express their affection towards each other. In addition, 1 man respondent (R13) thinks that the women in the video do not have the same attitude with women in general. R13 might believe that women in general tend to be more closed, while women in the video look open to other people. It could be interpreted that they talk freely because they seem that they could express themselves more.

3.
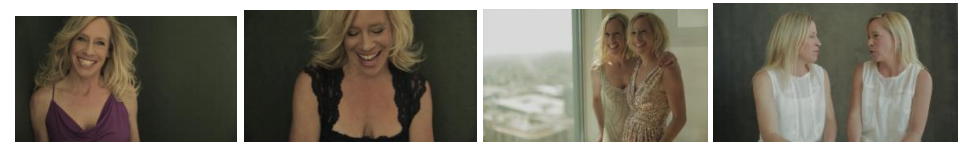

Figure 3. Pictures, photo shoot, and interview section

Based on these pictures, the writer asked question to 10 men respondents: What is the relation between those attitudes with beauty?. First of all, 2 men respondents (R13, R20) thought that relation between those attitudes with beauty comes from the society's perspective. Here, it might be interpreted that women in the video might have more self esteem in which they may love and be happy with themselves of who they are. In addition, 8 men respondents (R11, R12, R14, R15, R16, R17, R18, and R19) agreed that it is related with appearance and attitude. Here, it might be interpreted that women in the video could make others, including the respondents, comfortable and happy since they have the same attitude with women in general.

4.

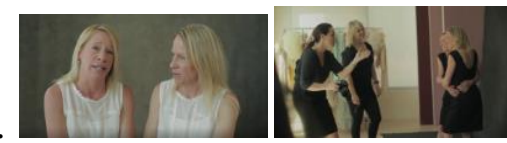

Figure 4. Second interview and photo shoot section pictures

Based on the pictures above, the writer asked question to 10 men respondents: Do you think the women here like their own face and body?. All 10 men respondents (R11, R12, R13, R14, R15, R16, R17, R18, R19 and R20) agreed that women in the video like their own face and body from psychological perspective. Here it might be interpreted that women in the video like to do self praising in order to boost their confidence. Moreover, 4 men respondents (R14, R16, R18, and R20) agreed that women in the video like their own face and body from their attitude: complimenting. It could be interpreted that women like their own face and body because they might seem like they do not complain about their face and body; but they do self praising.

5 .

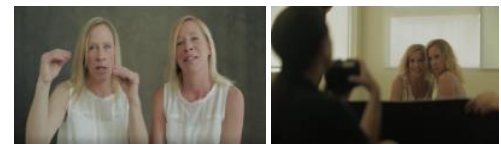


Figure 5. Women's talks and pose when they are being photographed

Based on these pictures above, the writer asked question to 10 men respondents: Do you think the women in the video look confident?. For the first analysis, all 10 men respondents (R11, R12, R13, R14, R15, R16, R17, R18, R19 and R20) agreed that women in the video look confident from psychological perspective. It might be interpreted that if the women were not confident, they would probably do not join this beauty campaign, because if they wanted to join this campaign, they need to be photographed. Next, all 10 men respondents (R11, R12, R13, R14, R15, R16, R17, R18, R19 and R20) agreed that women in the video look confident from the way they talk. It might mean that they look enthusiastically when they talk so that they could speak loudly and passionately

- The analysis of perceived meanings from men respondents (verbal data)

Here are the analyses for the perceived meanings with the verbal data.

1. We feel most beautiful when we're together

For the first analysis, all 10 men respondents (R11, R12, R13, R14, R15, R16, R17, R18, R19, and R20) perceived that it is related with their closed relationship. It might be interpreted that when they are together, they know each other best, and could give advice and suggestion to each other which make them look better; and because of that, they feel that they are most beautiful when they are together. In addition, 3 men respondents (R12, R14, and R20) perceived that it is related with being twins. It might be interpreted that twins are center of attention, in which people may always see them and become the topics that they talk whenever they go together.

2. Her skin looks flawless and beautiful

Firstly, 5 men respondents (R11, R13, R14, R15, and R18) perceived that it is related with their closed relationship. It could be interpreted that by complimenting each other, it actually may show that she wants to make her sister happy and feel good. Moreover, all 10 men respondents (R11, R12, R13, R14, R15, R16, R17, R18, R19, and R20) perceive it from psychological perspective and attitude. It could be interpreted that the women seem never having a negative thought about themselves, but always say and have self-praising that she is still beautiful and her skin still looks flawless.

3. I don't think we're aging because I don't feel my age

5 men respondents (R12, R16, R17, R18, and R20) perceived that it is because of psychological perspective. It might be interpreted that positive thinking make the women in the video look confident; whereas if the women had negative thought, it would bring them down and lower their confidence. Secondly, all 10 (R11, R13, R14, R15, R16, R17, R18, R19 and R20) women respondents perceived it as having spirit like youngsters. Here, it could be interpreted that women in the video might be confident since they wear dress and sleeveless shirt like youngsters do. Not aging always be interpreted as the face and body look younger (Signifier), but "Not aging" can have another meaning for the respondents interpret the women as having young spirit (Signified): passionate, excited, and like new or challenging stuffs (Process of Signification, Chandler, 2007).

4. I have got my sister who can give me the confidence

For the first analysis, 9 men respondents (R11, R13, R14, R15, R16, R17, R18, R19 and R20) perceived that it is because of their close relationship. It might be interpreted that compliments can boost her self-esteem. Her sister might give her a genuine praise that can be a positivity boost. Moreover, 6 men respondents (R11, R12, R13, R14, R15, and R17) think that it is related with mirror reflection. Since they are twins, they look like mirror reflection to each other. When she looks at her sister and compliments her, it might actually show that she also compliments herself, in which it could make her become confident. 
5. She makes me feel better about myself

For the first analysis, all 10 men respondents (R11, R12, R13, R14, R15, R16, R17, R18, R19 and R20) perceived that it is because of their close relationship. It might be interpreted that she will do what her sister said when she does wrong things and maybe, she will not do it if her friends admonish her, since the one who understands her better is only her sister. Moreover, 2 men respondents (R12 and R19) perceive that it may be related with being confident. In this case, it might be interpreted that she feels comfortable.

- The similarities between women and men respondents' perceived meanings in nonverbal data

The first similarity is that both women and men respondents agree that the women in the video are beautiful from the psychological perspective which is confident and always smile. Secondly, both women and men respondents agree that their attitude suits with women in general because they always smile a lot and the way their talk is gentle and calm.

- The similarities between women and men respondents' perceived meanings in verbal data

In the verbal data, both women and men respondents perceive "We feel most beautiful when we are together", because of their closed relationship which always help and support each other, and because they are twins. Both of them think that twins are somewhat more attractive. Secondly, in "Her skin looks flawless and beautiful", both of them produce similar perceive meanings in which the women say that because they love each other; they are confident; and it is related with Olay products.

- The differences between women and men respondents' perceived meanings in nonverbal data

The first difference that the writer finds is that women respondents think they are beautiful from their face appearance, while men respondents emphasize on their body proportion. Second difference, all women respondents agree that the women are beautiful, while in men respondents, there is only 1 man who thinks that they are not beautiful. Thirdly, all women respondents also agree that the women's attitudes suit with women in general, but in men respondents, there is only 1 man who thinks that their attitudes do not suit with women in general because they are confident and women in general not.

- The differences between women and men respondents' perceived meanings in verbal data

Both men and women respondents think that "We feel most beautiful when we are together", is related with being powerful. Here, women respondents perceive it as not afraid with anything, such as bad rumors, gossips, or mocks. While men respondents think that it is related with being stronger in life. Moreover, both men and women respondents think that "I have got my sister who can give me the confidence", is related with mirror reflection. Here, there is only 1 woman respondent who relates it with mirror reflection; while in men respondents; there are 6 respondents who relate it with mirror reflection.

\section{CONCLUSION AND SUGGESTIONS}

Indeed, both men and women respondents produced some similarities and differences in producing perceived meanings. After that, the writer identified some similarities and differences produced by these two groups. In the findings, the writer found that women respondents' perceived meanings tend to relate the women in the video with themselves about beauty and their own experience, and relationship with their sisters; while men respondents are most likely to relate it with their ideal type of women. Some of men respondents also talk about their experience dealing with older people and other female friends, but mostly relate them with their ideal type of women. Finally, the writer recommends researches on perceived meanings from other advertisements by looking at other factors than gender, such as age, or ethnicity. Thus, the writer also hopes that it could be a source of information for those who want to do the research on semiotic analysis. 


\section{REFERENCES}

Barthes, R. (1987). Mythologies. New York: Hill \& Wang Chandler, D. (2007). Semiotics The Basics (2nd ed). London: Routledge.

Hall, Stuart. (1980): 'Encoding/decoding'. In Centre for Contemporary Cultural Studies (Ed.): Culture, Media, Language: Working Papers in Cultural Studies, 1972-79 London: Hutchinson, pp. 128-38

Olay North America (2014, October 15). Identical Twins and Best Friends $\mid$ OlayPro-X. $\quad$ Retrieved $\quad$ February $22, \quad 2017$, from https://www.youtube.com/watch?v=c8bq0tHPCkA

PT. Unilever, Tbk. (2017). The Dove ${ }^{\circledR}$ Campaign for Real Beauty. Retrieved March 17, 2017 from http://www.dove.com/us/en/stories/about-dove/ourresearch.html

Schreier, M. (2012). Qualitative Content Analysis in Practice. Los Angeles: SAGE Publications.

Swami, V. et.al. (2010, November 6). More than just skin deep? Personality Information Influences Men's Ratings of the Attractiveness of Women's Body Sizes. The Journal of Social Psychology., 150 (6), 628-647. Retrieved June 16, 2017 from http://www.tandfonline.com/doi/abs/10.1080/00224540903365497 